\title{
Molecular cloning and sequence of Sparus aurata skeletal myosin light chains expressed in white muscle: developmental expression and thyroid regulation
}

\author{
Katerina A. Moutou ${ }^{1, *}$, Adelino V. M. Canario ${ }^{2}$, Zissis Mamuris ${ }^{1}$ and Deborah M. Power ${ }^{2}$ \\ ${ }^{1}$ Department of Biochemistry and Biotechnology, University of Thessaly, 26 Ploutonos Street, 41221 Larissa, Greece \\ and ${ }^{2}$ Centre of Marine Sciences (CCMAR), University of Algarve, Campus de Gambelas, 8000 Faro, Portugal
}

*Author for correspondence (e-mail: kmoutou@uth.gr)

Accepted 13 June 2001

\begin{abstract}
Summary
Two full-length cDNA clones encoding the skeletal myosin light chain 2 (MLC2; 1452 bp) and myosin light chain 3 (MLC3; 972 bp) were isolated from a cDNA library prepared from gilthead sea bream Sparus aurata larvae. The MLC2 cDNA encoded a predicted protein of 170 residues that was $79 \%$ identical to rabbit MLC2 over the entire length and $87 \%$ identical within the $\mathrm{Ca}^{2+}$ binding region. The deduced amino acid sequence of MLC3 was 153 residues in length and was $91 \%$ and $69 \%$ identical to the zebrafish and rabbit MLC3, respectively. Northern blot analysis revealed that in adults both transcripts were expressed in fast white muscle only. MLC2 appeared earlier in development: MLC2

second MLC2 transcript of 0.89 kilobase-pairs was present. MLCs exhibited a different age-related pattern of response to varied thyroidal states, which were experimentally induced by the administration of $1 \mu \mathrm{g} \mathrm{g}^{-1}$ body mass of thyroxine (T4) or triiodothyronine (T3), or $5 \mathrm{ng} \mathrm{g}^{-1}$ body mass of the hypothyroidal compound thiourea; MLC3 expression was not significantly affected, whereas levels of MLC2 transcripts were significantly elevated in the white muscle only of juvenile sea bream after administration of T4. Although the mechanism of thyroidal regulation of MLC expression remains unknown, the present results suggest that different regulatory mechanisms exist for different MLCs.
\end{abstract} transcripts were detectable from the beginning of segmentation, whereas MLC3 transcripts did not appear until $27 \mathrm{~h}$ post-fertilisation. At this developmental stage, a
Key words: sea bream, Sparus aurata, myosin light chain, white muscle, development, thyroid regulation.

\section{Introduction}

Myosin, the major protein component of striated muscle tissues, consists of two heavy chains (MHCs) and four light chains (MLCs), which combine to form a long coiled $\alpha$-helical tail and two heads. Each head contains an actin-binding site and ATPase activity. The formation of the head structure involves the N-terminal half of two MHCs and one pair of light chains (Lowey, 1994). The light chains belong to the troponin$\mathrm{C}$ supergene family that also includes the $\mathrm{Ca}^{2+}$-binding proteins calmodulin and parvalbumin (Periasamy et al., 1984). The light chains are classified into two classes: the alkali- and dinitrobenzoic acid (DTNB)-removable light chains (Weeds and Lowey, 1971). In skeletal muscle, there are two different types of alkali light chain, MLC1 and MLC3. An association between the alkali light chains and the MHC head region has been documented; it is believed to be involved in the interaction between myosin and actin, and a linear correlation has been reported between the MLC1:MLC3 ratio and the shortening velocity of the contractile apparatus (Lowey and Trybus, 1995). The DTNB-removable light chains are termed MLC2 and have a regulatory if not a catalytic role binding $\mathrm{Ca}^{2+}$ and are, therefore, commonly referred to as regulatory light chains (Weeds and Lowey, 1971).
Both MHCs and MLCs exist in multiple isoforms that show tissue-specific and/or developmental-stage-specific distribution, and their expression is known to be under environmental and hormonal control (Whalen et al., 1981; Gauthier et al., 1982; Izumo et al., 1986; Yamano et al., 1994; Hill et al., 2000). As is the case for other vertebrates, fish skeletal muscle myosins contain two alkali light chains, MLC1 and MLC3, and a regulatory light chain, MLC2. Different isoforms have been isolated and characterised from skeletal muscle of fish in an attempt to understand their contribution to muscle growth and contractile properties and their regulation during development and by environmental factors such as temperature, diet and exercise (Perzanowska et al., 1978; Rowlerson et al., 1985; Ochiai et al., 1988; Johnston, 1994; Hirayama et al., 1997; Hirayama et al., 1998; Johnston et al., 1998; Xu et al., 1999; Hill et al., 2000). Their expression patterns in fish present further interest; skeletal muscle growth in fish occurs both by hyperplasia and by hypertrophy throughout much of their life cycle, in contrast to mammals, in which hyperplasia is restricted largely to the pre- and perinatal period (Johnston et al., 1998). In this way, fish provide a model for the study of muscle development and the mechanisms underlying muscle cellularity. 


\section{K. A. Moutou AND OTHERS}

In mammals and birds, thyroid hormone has been reported to be one of the major factors that control the developmental transition of myosin isoforms (Gambke et al., 1983; ButlerBrowne et al., 1984; Gardahaut et al., 1992). In fish, larval development has been positively correlated with the plasma triiodothyronine (T3) concentrations of prespawning females and the amount of maternal thyroid hormones transferred into fish eggs (Ayson and Lam, 1983; Brown et al., 1988; Brown et al., 1989). More interestingly, thyroid hormone has been shown to hold a key role in the metamorphosis of the larvae of Japanese flounder Paralichthys olivaceus, regulating the transition of the DTNB-removable light chains (MLC2) from the larval to the adult type (Yamano et al., 1994).

In this study, we report the molecular cloning and sequence of skeletal myosin light chains 2 and 3 of gilthead sea bream Sparus aurata. The tissue and developmental expression of MLCs is described. Hyper- and hypothyrodism were induced by the administration of triiodothyronine (T3) or thyroxine (T4) and the hypothyroidal drug thiourea, respectively, and the effects of thyroidal status on the expression levels of MLCs in the white muscle were examined in relation to age.

\section{Materials and methods}

Juvenile sea bream (Sparus aurata) maintained in throughflow seawater tanks at $17 \pm 2{ }^{\circ} \mathrm{C}$ under the natural photoperiod for winter in the Algarve, Portugal, were killed by stunning and decapitation. Liver, kidney, intestine, brain, gills, skeletal muscle and heart were immediately dissected out, frozen in liquid nitrogen and stored at $-70^{\circ} \mathrm{C}$. Larvae were cultured using standard methods and sampled.

\section{Treatment with thyroid hormones}

The effects of thyroidal state on the levels of expression of the two MLCs and the differential effects of age were determined in sea bream of two different ages after administering T3, T4 or the hypothyroidal compound thiourea (an inhibitor of the synthesis of endogenous thyroid hormone; Yamano et al., 1994). 48 gilthead sea bream of mass $329 \mathrm{~g} \pm 9.77 \mathrm{~g}$ (adult) and $48 \mathrm{fish}$ of mass $7.35 \mathrm{~g} \pm 0.36 \mathrm{~g}$ (juvenile) (means \pm S.E.M.) were allocated to eight experimental groups that contained 12 adult or juvenile fish each. The groups were kept indoors in separate tanks and were fed once a day ad libitum. The water temperature during the experiments ranged between 26 and $27^{\circ} \mathrm{C}$ and the photoperiod was $12 \mathrm{~h}: 12 \mathrm{~h} \mathrm{~L}: \mathrm{D}$.

On day 1 of the experiment, one group of each age class (adult or juvenile) was administered T3, T4 or thiourea, as a single intraperitoneal injection using coconut oil as a carrier at a ratio of $10 \mu \mathrm{l}$ coconut oil: $1 \mathrm{~g}$ body mass. The doses used were: T3, $1 \mu \mathrm{g} \mathrm{g}^{-1}$ body mass; $\mathrm{T} 4,1 \mu \mathrm{g} \mathrm{g}^{-1}$ body mass; thiourea, $5 \mathrm{ng} \mathrm{g}^{-1}$ body mass. In control fish, $10 \mu \mathrm{l}$ coconut oil $\mathrm{g}^{-1}$ body mass was administered alone.

Fish were sampled for determination of the levels of MLC2 and MLC3 transcripts on days 2, 3, 5 and 8 of the experiment. On each occasion white muscle from three fish of each group was sampled from the area under the dorsal fin. The muscle sample was dipped immediately in chilled TRI reagent (Sigma, St Louis, MO, USA) and homogenised. Total RNA was extracted within $24 \mathrm{~h}$.

The efficacy of these treatments was assessed by measuring plasma T4 and T3 levels on the second and third days of the experiment. Blood samples were obtained from three individuals per treatment from the caudal vasculature, and plasma was separated by centrifugation and stored at $-20{ }^{\circ} \mathrm{C}$ until assayed. Plasma T3 and T4 levels were determined by radioimmunoassay (RIA) (as described by Power et al., 2000).

Generation of an homologous myosin light chain cDNA probe by reverse transcription-polymerase chain reaction

$$
\text { (RT-PCR) }
$$

Myosin alkali light chain 3 (MLC3) and regulatory light chain 2 (MLC2) cDNAs were cloned by using degenerated primers to amplify a 406 base-pair (bp) and a 511 bp fragment respectively. PCR primers were designed within the most highly conserved regions of both MLC2 and MLC3, identified after multiple sequence alignments of all MLC sequences available (GenBank). A forward primer based on a highly conserved region (EEFKEA), common to both light chains, was synthesised (5' GARGARTTYAARGARGC 3'; Pharmacia Biotech, Uppsala), and the reverse primer was 5' GCYTCRTARTTRATRCANCCRTT 3'.

cDNA was synthesised from $1 \mu \mathrm{g}$ of white muscle total RNA and PCR was carried out in a reaction $(50 \mu \mathrm{l})$ containing $5 \mu \mathrm{l}$ of white muscle cDNA, $10 \mathrm{mmoll}^{-1}$ Tris- $\mathrm{HCl}, \mathrm{pH} 9.0$, $50 \mathrm{mmoll}^{-1} \mathrm{KCl}, 0.1 \%$ Triton $\mathrm{X}-100,2.5 \mathrm{mmoll}^{-1} \mathrm{MgCl}_{2}$, $1 \mathrm{mmoll}^{-1}$ each deoxynucleotide triphosphate, $200 \mathrm{pmol}$ of forward primer, $200 \mathrm{pmol}$ of reverse primer and Taq DNA polymerase (5 units; Promega, Madison, WI, USA). The cDNA template was amplified after an initial denaturing step at $94^{\circ} \mathrm{C}$ for $2 \mathrm{~min}$, using 20 cycles of the following PCR protocol: $94^{\circ} \mathrm{C}$ for $1 \mathrm{~min}, 50^{\circ} \mathrm{C}$ for $2 \mathrm{~min}$ and $72^{\circ} \mathrm{C}$ for $1 \mathrm{~min}$. PCR products corresponding to the expected size were cloned using the pGEM-T Easy cloning system (Promega) and sequenced. Two of the cloned and sequenced PCR products were subsequently used as probes to screen a sea bream larva cDNA library for MLC2 and MLC3.

\section{cDNA library screening}

A sea bream larva cDNA library was constructed in the vector Lamba ZapII with reverse-transcribed cDNA obtained from $5 \mu \mathrm{g}$ of poly $(\mathrm{A})^{+}$mRNA, obtained from total RNA by chromatography on columns of oligo-dT cellulose. Homologous probes for MLC2 (511 bp) and MLC3 (406 bp), generated by RT-PCR, were used to screen the library under high-stringency conditions. Duplicate membranes (Hybond-C, Amersham) were hybridised with the $\left[\alpha_{-}{ }^{32} \mathrm{P}\right] \mathrm{dCTP}-$ labelled probe overnight at $65^{\circ} \mathrm{C}$. Stringency washes were carried out at $65^{\circ} \mathrm{C}$ with $0.1 \times \mathrm{SSC}\left(1 \times \mathrm{SSC}\right.$ is $0.15 \mathrm{~mol}^{-1}$ sodium chloride, $0.015 \mathrm{~mol}^{-1}$ sodium citrate) containing $0.1 \%$ SDS. Positive clones were isolated and excised from the ZapII vector into pBluescript SK(-) (Stratagene) and fully sequenced using the 
dideoxy chain termination procedure (Sanger et al., 1977) using a Licor DNA4200 automated sequencer (MWG Biotech, UK). Positive clones corresponding to each myosin light chain were sequenced three times.

\section{Phylogenetic analysis}

Previously published MLC sequences were obtained from the GenBank database and used for amino acid comparison and phylogenetic analyses. The following is the list of accession numbers for the skeletal MLC2 sequences. Mammalian: P41691, Felis catus superfast MLC2 (Qin et al., 1994); Q02045, Homo sapiens superfast MLC2 (Collins et al., 1992); P24732, Oryctolagus cuniculus (Maeda et al., 1990); P04466, Rattus norvegicus (Nudel et al., 1984); P97457, Mus musculus (Palermo et al., 1995); Avian: P02609, Gallus gallus (Suzuyama et al., 1980); Piscine: AAF71271, Oncorhynchus kisutch (Hill et al., 2000); AAC32193, Danio rerio (Xu et al., 1999); AAF00097, Danio rerio cardiac MLC2 (Yelon et al., 1999); BAA95142, Engraulis japonicus; BAA95140, Sardinops melanostictus; BAA95125, Thunnus thynnus; BAA95128, Euthynnus pelamis; BAA95131, Pennahia argentata; BAA95134, Cypselurus agoo; BAA95137, Trachurus trachurus; BAA89705, Cyprinus carpio (Hirayama et al., 1998).

The following is the list of accession numbers for the skeletal MLC3 sequences. Mammalian: NP000249, Homo sapiens (Cohen-Haguenauer et al., 1989); CAA37977, Oryctolagus cuniculus (Muller et al., 1990); P02601, Rattus norvegicus (Strehler et al., 1985); P05978, Mus musculus (Robert et al., 1984); CAA64353, Sus scrofa (Davoli et al., 1997); Q60605, Mus musculus non-muscle MLC3 (Hailstones and Gunning, 1994); Avian: P02605, Gallus gallus (Nabeshima et al., 1982); Piscine: BAA94860, Danio rerio; BAA95139, Sardinops melanostictus; BAA95124, Thunnus thynnus; BAA95127, Euthynnus pelamis; BAA95130, Pennahia argentata; BAA95133, Cypselurus agoo; BAA95136, Trachurus trachurus; BAA12733, Cyprinus carpio (Hirayama et al., 1997).

The amino acid sequences were aligned using the Clustal W program (Thompson et al., 1994). Evolutionary distances were estimated using Kimura's empirical method for proteins (Kimura, 1983), and phylogenetic trees were constructed by the neighbour-joining method (Saitou and Nei, 1987) using PHYLIP (Felsenstein, 1993). 100 bootstrap analyses were performed for the phylogenetic analysis.

\section{Northern blot analysis}

Northern blot analysis was performed to determine the expression of the MLCs in a variety of tissues of adult sea bream and at different developmental stages and to check differential expression in white muscle following administration of T4, T3 or thiourea. To assess the effects of T3, T4 or thiourea treatment on the expression of the different forms of MLC, densitometry was carried out on the resulting autoradiograph for each probe and results were normalised against the expression of cytoplasmic $\beta$-actin, expression of which was unmodified by the various treatments. Exposure times of $30 \mathrm{~min}, 1 \mathrm{~h}, 2 \mathrm{~h}$ and $3 \mathrm{~h}$ were tested to ensure that the time chosen for densitometric quantification (30 min) fell within the linear range of the photographic technique.

Total RNA $(5 \mu \mathrm{g})$ from a variety of tissues of adult sea bream, from whole fertilised eggs at different developmental stages and from white muscle of untreated sea bream and sea bream treated with $\mathrm{T} 4, \mathrm{~T} 3$ or thiourea was fractionated on a formaldehyde gel and transferred to Hybond-N nylon membranes (Amersham) with $10 \times \mathrm{SSC}$ and crosslinked at $80^{\circ} \mathrm{C}$ for $2 \mathrm{~h}$. Hybridisation was performed sequentially with $\left[\alpha-{ }^{32} \mathrm{P}\right] \mathrm{dCTP}-$ labelled full-length MLC2 and MLC3 probes. Membranes were hybridised first with $\beta$-actin, then with MLC2 and finally with MLC3. The order of probing the membrane with MLC2 or MLC3 did not appear to affect the outcome of the results. The first probe hybridised to the membrane was always $\beta$-actin. Film was exposed over the time range indicated and used for densitometry. Subsequently, membranes were washed with hybridisation solution, prehybridised and hybridised to MLC3 or MLC2. Stringency

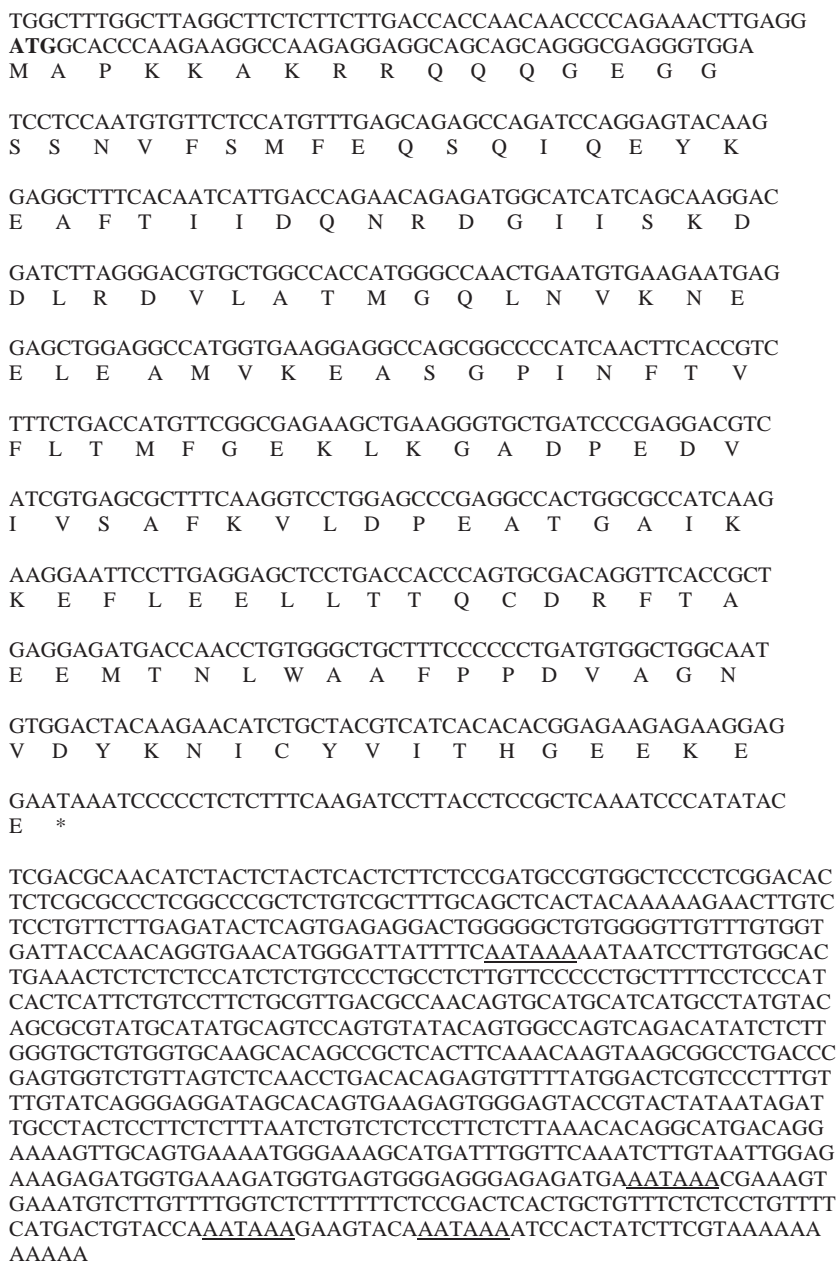

TCGACGCAACATCTACTCTACTCACTCTTCTCCGATGCCGTGGCTCCCTCGGACAC TCTCGCGCCCTCGGCCCGCTCTGTCGCTTTGCAGCTCACTACAAAAAGAACTTGTC TCCTGTTCTTGAGATACTCAGTGAGAGGACTGGGGGCTGTGGGGTTGTTTGTGGT GATTACCAACAGGTGAACATGGGATTATTTTCAATAAAAATAATCCTTGTGGCAC TGAAACTCTCTCTCCATCTCTGTCCCTGCCTCTTGTTCCCCCTGCTTTTCCTCCCAT CACTCATTCTGTCCTTCTGCGTTGACGCCAACAGTGCATGCATCATGCCTATGTAC AGCGCGTATGCATATGCAGTCCAGTGTATACAGTGGCCAGTCAGACATATCTCTT GGGTGCTGTGGTGCAAGCACAGCCGCTCACTTCAAACAAGTAAGCGGCCTGACCC GAGTGGTCTGTTAGTCTCAACCTGACACAGAGTGTTTTATGGACTCGTCCCTTTGT TTGTATCAGGGAGGATAGCACAGTGAAGAGTGGGAGTACCGTACTATAATAGAT TGCCTACTCCTTCTCTTTAATCTGTCTCTCCTTCTCTTAAACACAGGCATGACAGG AAAAGTTGCAGTGAAAATGGGAAAGCATGATTTGGTTCAAATCTTGTAATTGGAG AAAGAGATGGTGAAAGATGGTGAGTGGGAGGGAGAGATGAAATAAACGAAAGT GAAATGTCTTGTTTTGGTCTCTTTTTTCTCCGACTCACTGCTGTTTCTCTCCTGTTTT CATGACTGTACCAAATAAAGAAGTACAAATAAAATCCACTATCTTCGTAAAAAA AAAAA

Fig. 1. Nucleotide and deduced amino acid sequence of the Sparus aurata myosin light chain 2 . The polyadenylation signals are underlined and the start codon is bold. 


\section{K. A. Moutou AND OTHERS}

washes were carried out at $60^{\circ} \mathrm{C}$ with $1 \times \mathrm{SSC}$ containing $0.1 \%$ SDS. Film was exposed to membrane, and densitometry analysis was carried out on the resulting film. The same procedure was carried out for the final probe (MLC2 or MLC3). The final film exposed contained all the signals (since membrane was not stripped between probing) but was used to scan by densitometry only the transcript corresponding to the probe used. The consistency of RNA loading for the northern blot had previously been checked by fractionation of samples on mini-agarose gels and observing the intensity of $18 \mathrm{~S}$ and $28 \mathrm{~S}$ ribosomal RNA bands after staining with ethidium bromide. Three different northern blots were conducted with the same samples to ensure reproducibility of the technique.

\section{Statistical analyses}

Results for northern blot analysis are expressed as arbitrary units of mRNA levels, means \pm S.E.M. of four samples, normalised against the quantity of total RNA by $\beta$-actin expression. Each sample consisted of a pool of the three individuals sampled on each experimental day. Two-way analysis of variance (ANOVA) was performed between fish of different age and between different treatments. One-way ANOVA was performed for plasma T4 and T3 levels and for the effects of thyroid hormones (T3 and T4) and thiourea on the expression of myosin light chains. To establish differences between means, an unpaired two-tailed Student's $t$-test was used. Variables were considered significantly different at $P<0.05$ (Zar, 1996).

\section{Results}

\section{Isolation and identification of the MLC cDNA clones}

MLC cDNAs were isolated after screening a cDNA library prepared from sea bream larvae 1-10 days after hatching. Two different clones were isolated. One clone was 1452 bp long with an open reading frame of 513 nucleotides, starting at the first ATG codon located 55 nucleotides from the $5^{\prime}$ terminal region of the clone and ending with a TAA stop codon (Fig. 1). The 3' untranslated region was $885 \mathrm{bp}$ long and contained multiple potential polyadenylation signals (AATAAA). The deduced amino acid sequence was 170 amino acid residues in extent and it coded for the skeletal myosin regulatory light chain 2 (MLC2). The MLC2 clone showed a strong similarity to zebrafish (Danio rerio) MLC2 (95\% identical) and even to rabbit (Oryctolagus cuniculus) MLC2 (79\% identical). An alignment of the predicted amino acid sequences of skeletal MLC2 deposited in GenBank is presented in Fig. 2. The $\mathrm{Ca}^{2+}$ binding area (residues 39-53) exhibits a high degree of

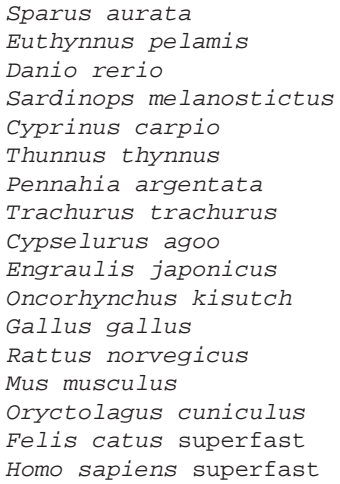

Fig. 2. Alignment of the deduced amino acid sequences of the myosin light chain 2 (MLC2) proteins. The $\mathrm{Ca}^{2+}$-binding domain is indicated in bold type. Conserved residues are marked by an asterisk; conservative differences are marked by a full point. Sources, references and accession numbers are described in Materials and methods. 
CAACTCTCCAACATGACCGAACAGGCCGAGTTCAGTGCCGACCAGATTGAG $\begin{array}{lllllllllllll}M & \mathrm{~T} & \mathrm{E} & \mathrm{K} & \mathrm{A} & \mathrm{E} & \mathrm{F} & \mathrm{S} & \mathrm{A} & \mathrm{D} & \mathrm{Q} & \mathrm{I} & \mathrm{E}\end{array}$

GACTTCAAGGAGGCTTTCGGTCTCTTTGACAGAGTCGGTGACAGCCAGGT $\begin{array}{llllllllllllllllll}D & F & K & E & A & F & G & L & F & D & R & V & G & D & N & K & V\end{array}$

GCCTTCAACCAGGTTGCTGACATCATGCGCGCTCTGGGCCAGAACCCCACC $\begin{array}{lllllllllllllllll}\text { A } & \text { Y } & \text { N } & \text { Q } & \text { V } & \text { A } & \text { D } & \text { I } & \text { M } & \text { R } & \text { A } & \text { L } & \text { G } & \text { Q } & \text { N } & \text { P } & \text { T }\end{array}$

AACAAGGACGTTACAAAGATTCTGGGCAACCCCTCCGCCGACGACATGGCC $\begin{array}{lllllllllllllllll}\mathrm{N} & \mathrm{K} & \mathrm{D} & \mathrm{V} & \mathrm{T} & \mathrm{K} & \mathrm{I} & \mathrm{L} & \mathrm{G} & \mathrm{N} & \mathrm{P} & \mathrm{S} & \mathrm{A} & \mathrm{D} & \mathrm{D} & \mathrm{M} & \mathrm{A}\end{array}$

AACAAGAGGCTCAACTTCGAGGCTTTCCTGCCCATGCTGAAGGAGGTCGAC $\begin{array}{lllllllllllllllll}\mathrm{N} & \mathrm{K} & \mathrm{R} & \mathrm{L} & \mathrm{N} & \mathrm{F} & \mathrm{E} & \mathrm{A} & \mathrm{F} & \mathrm{L} & \mathrm{P} & \mathrm{M} & \mathrm{L} & \mathrm{K} & \mathrm{E} & \mathrm{V} & \mathrm{D}\end{array}$

GCCTTGCAGAAGGGCACCTACGACGACTACGTTGAGGGCCTGCGCGTCTTC $\begin{array}{lllllllllllllllll}\text { A } & \mathrm{L} & \mathrm{Q} & \mathrm{K} & \mathrm{G} & \mathrm{T} & \mathrm{Y} & \mathrm{D} & \mathrm{D} & \mathrm{Y} & \mathrm{V} & \mathrm{E} & \mathrm{G} & \mathrm{L} & \mathrm{R} & \mathrm{V} & \mathrm{F}\end{array}$

GACAAGGAGGGCAACGGCACAGTCATGGGCGCTGAGCTGCGCATCGTGCTG $\begin{array}{lllllllllllllllll}D & K & E & G & N & G & T & V & M & G & A & E & L & R & \text { I } & \text { V } & \text { L }\end{array}$

TCCACCCTGGGAGAGAAGATGACCGAGCCTGAGATTGATGCCCTCATGGCC $\begin{array}{lllllllllllllllll}S & T & L & G & E & K & M & T & E & P & E & I & D & A & L & M & A\end{array}$

GGCCAGGAGGACGAGAACGGCAGTTTGCACTATGAGGCTTTCGTCAAGCAC $\begin{array}{llllllllllllllllll}G & Q & E & D & E & N & G & S & V & H & Y & E & A & F & V & K & H\end{array}$

ATCATGTCTGTGTAAGAGGCCGGCAGCAGGAGTGCTGAAGAACAGCCCGAC I $\quad M \quad S \quad V$

GGTGTTCAGGACATCTACACTGTTGTCAAAGACCAACCAAGGA AAGACAAGGAC TATGTACAAGGGATGTTGAAGCAAACCCATCTTGTTGTTTTATTTTGTTTTTCCCTT TCCATTTCGTCTCACMCSCCCTCCTCCCTCTCTCGGGACGCCACCATCACCTCTAC ACCGTAGACCCACCACCACTCGGCCTCCACTCCCCCCTACCCTCCGGGGCACGTC TACACATGCGCATGGGTGAGGAACGGGGAAAAGGGGTGAGCGCTCATCAAGTGA GGGTAGATCCTCCCTTCCCACCGCCACTCATTCAGTCTCGCCATCACTGGTCCAGC AATGCAAAGGTGCTGAGAATGGTCGTGGATAGACGCCAAAAAAGTCTCCCCGCTT CCCTGAAAAGTTTTATTTATTGTCACTCTGTTCATGTCAGAATAAACTTTTCCAAC GTAAAAA AAAAAAAAAAA

Fig. 3. Nucleotide and deduced amino acid sequence of the Sparus aurata myosin light chain 3 . The polyadenylation signal is underlined and the start codon is bold.

conservation showing $100 \%$ identity to $D$. rerio and $87 \%$ to O. cuniculus proteins in this region.

The other clone contained $972 \mathrm{bp}$ and encodes an open reading frame of 462 nucleotides (Fig. 3). The first translation codon is 13 nucleotides downstream from the start of the clone, which ends with a TAA codon. The 3' untranslated region was 498 nucleotides long and contained a polyadenylation signal (AATAAA) 18 nucleotides upstream from the poly(A) tail. The deduced amino acid sequence was 153 amino acid residues long and encoded a skeletal myosin light chain 3 (MLC3). The region corresponding to the common MLC1/3 domain of avian and mammalian species (residues 14-153) proteins appeared to be very well conserved with $91 \%$ similarity to $D$. rerio and $67 \%$ to $O$. cuniculus proteins (Fig. 4). In contrast, the sequence of the N-terminal region of the protein appeared to be more variable (Fig. 4); in avian and mammalian species, this region is nine amino acid residues long defining the MLC3-specific domain, whereas in some fish it can reach the 32 residues in length (Fig. 4).

\section{Appearance of MLCs in juvenile tissues and during development}

In juvenile fish, MLC2 and MLC3 transcripts were detected as single species of approximately 1.56 and 1.10 kilobases $(\mathrm{kb})$ respectively (Fig. 5A). The transcript sizes were in agreement with the sizes of the clones isolated. White muscle was found to be the only tissue in which both transcripts were detectable. MLC3 appeared to be more abundant than MLC2. In no other type of muscle tissue (cardiac, red and smooth muscle) were transcripts of either MLC present.

No maternal mRNA of either MLC was detected in unfertilised eggs (Fig. 5B). During development, the expression profile of MLC2 matched the process of segmentation; there was no evidence of expression at blastula stages, and initiation of expression was marked at approximately $22 \mathrm{~h}$ post-fertilisation (h.p.f.) (Fig. 5B). A gradual accumulation of transcripts was observed as development proceeded. By 27 h.p.f. a second transcript of MLC2 of approximately $0.89 \mathrm{~kb}$ was detectable. MLC3 transcripts, in contrast, were not detected as early as MLC2, and the onset of expression occurred at approximately the same time as the expression of the second MLC2 form (27 h.p.f.).

\section{Effect of thyroidal status on the expression of myosin light chains}

In control sea bream, both MLC2 $(F=97.6, P<0.01)$ and MLC3 $(F=127.8, \quad P<0.01)$ transcripts were expressed at significantly higher levels in juvenile than in adult fish (Fig. 6). The magnitude of expression was higher for MLC3 (8.8-fold) than for MLC2 (3.8-fold). The ratio of expression MLC3:MLC2 was also higher in juvenile fish (4.4-fold) than in adult fish (1.9-fold), indicating an age-related pattern of the relative expression of MLCs, due mainly to higher levels of MLC3 expression at a younger age.

Plasma T3 levels were significantly affected by the different treatments $(F=20.99, P<0.01)$; they were significantly elevated following T3 (3.3-fold) and T4 (1.7-fold) administration, respectively, whereas thiourea led to a significant $38 \%$ decrease in plasma T3 levels (data not shown). Plasma T4 levels were also significantly altered by the different treatments $(F=35.33, P<0.01)$, with T4 and T3 administration leading to a 3.1- and a 1.9-fold increase, respectively. In contrast, administration of thiourea decreased $\mathrm{T} 4$ plasma levels to approximately half of those of control fish.

In juvenile fish, administration of $\mathrm{T} 4$ led to a significant increase in the level of expression of $\operatorname{MLC} 2(F=7.30, P<0.01)$, whereas it had no significant effect on the expression of MLC3 (Fig. 6). MLC2 transcript levels had almost doubled $24 \mathrm{~h}$ after T4 administration and remained elevated throughout the experimental period (Fig. 6A). Neither T3 nor thiourea administration significantly affected the accumulation of MLC transcripts (Fig. 6).

In adult fish, administration of $\mathrm{T} 4$ resulted in a slight, but not statistically significant, increase in expression of both MLC2 and MLC3 (Fig. 6). A gradual accumulation of MLC3 transcripts followed the administration of T4 (Fig. 6B). The highest value was reached on day 8. MLC2 expression followed almost the same pattern (Fig. 6A). However, expression levels of both MLC2 and MLC3 were unaffected by the administration of thiourea or $\mathrm{T} 3$. 


\section{K. A. Moutou AND OTHERS}

\section{Discussion}

The present study reports the isolation and sequence of myosin light chains (MLCs) 2 and 3 expressed in the white muscle only of sea bream. To investigate the evolutionary relationships between the MLC2 and MLC3 isoforms of $S$. aurata and other animals, a molecular phylogenetic analysis of MLC2 and MLC3 amino acid sequences was performed. Figs 7 and 8 present the phylogenetic trees of the deduced

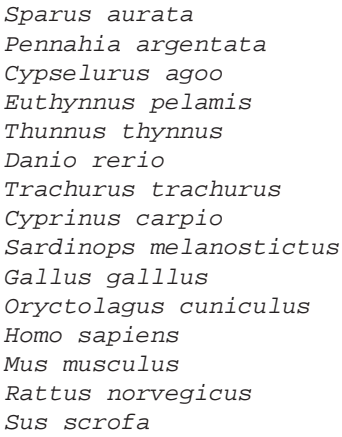

DFKEAFGLFDRVGD SOVAFNOVAD IMRALGONP TNKDVTK I LGNP SADDMANKR DFKEAFGIFDRVGDSOVAFNOVADIMRALGONPTNKDVTKI LGNPSADDMANKR DFKEAFGLFDRIGD SQVAFNQVAD IMRALGQNP TNKDVTKI LGNP SAEDMANKR DFKEAFGLFDRVGDNOVAFNOVADIMRALGONP TNKDVHKI LGNP SADDMANKR DFKEAFGLFDRVGDNOVAFNOVAD IMRALGONP TNKDVHKI LGNP TADDMANKR DFKEAFGLFDRVGD SKVAYNQVAD IMRALGQNP TNKDVKK ILGDP SADDMANKR DFKEAFGLFDRVGDGOVAYNOVAD IMRALGONP GNKDVTK I LGNP SADDMANKR DFKEAFGLFDRVGDNKVAYNQVAD IMRALGQNP TNKDVKK I LGDP SADDMANKR DFKEAFGLFDRVGDNQVGYNQVAD IMRALGQNP TNGEVKKLLGSP SVEDMANKR DFKEAFLLFDRTGDAKITLSOVGD IVRALGONPTNAE INK I LGNP SKEEMNAKK EFKEAFLLYDRTGDSKITLSQVGDVLRALGTNP TNAEVKKVLGNP SNEEMNAKK EFKEAFLLFDRTGDSKITLSQVGDVLRALGTNP TNAEVRKVLGNP SNEELNAKK DFKEAFLLFDRTGECK ITLSOVGDVLRALGTNPTNAEVKKVLGNP SNEEMNAKK EFKEAFLLFDRTGECKITLSQVGDVLRALGTNP TNAEVKKVLGNP SNEEMNAKK EFKEAFLLFDRTGECKITLSQVGDVLRALGTNP TNAEVKKVLGNP SNEEMNAKK

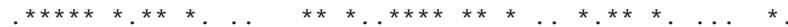

\author{
Sparus aurata \\ Pennahia argentata \\ Cypselurus agoo \\ Euthynnus pelamis \\ Thunnus thynnus \\ Danio rerio \\ Trachurus trachurus \\ Cyprinus carpio \\ Sardinops melanostictus \\ Gallus gallius \\ Oryctolagus cuniculus \\ Homo sapiens \\ Mus musculus \\ Rattus norvegicus \\ Sus scrofa
} DAAPPPAEAAPAAPAAPAAGGA MSF SPDQID $\star \star \star *$

MLC3-specific domain
LNE EAF LPMLKEV-DALQKGTYDDYVEGLRVFDKEGNGTVMGAELRIVLSTLGEKMTEP E IDALMAGQEDENGSLHYEAFVKHIMSV INFEAF LPMLKEV-DSOPKGTYDDYVEGLRVFDKEGNGTVMGAELRIVLSTLGEKMNETE IDALMAGQEDENGSVHYEAFVKH IMSV INFDAF LPMLKEV-DAMTKGTYDDYVEGLRVFDKEGNGTVMGAELRIVLSTLGEKMNEHE IDALMAGQEDENGSVHYEAFVKH IMSV LNFDTF LPMLKEV-DTYQKGTYDDYVEGLRVFDKEGNGTVMGAELRIVLSTLGEKMSEPE IDALMTGQEDENGSVHYEAFVKH IMSV LNFDTF LPMLKOV-DTFOKGTYDDYVEGLRVFDKEGNGTVMGAELRIVLSTLGEKMSEPE IDALMTGQEDENGSVHYEAFVKH IMSV IDFEAF LPMLKTV-DANQKGTYDDYVEGLRVFDKEGNGTVMGAELRIVLSTLGEKMSEPE IDALMQGQEDENGMVHYEAFVKNIMSV LAFDAF IPMLKQV-DALQKGTYDDYVEGLRVFDKEGNGTVMGAELRIVLSTLGEKMTEPE IDALMTGQEDENGSVHYEAFVKHIMSV IDFDAF LPMLKTV-DAVOKGTYDDYVEGLRVFDKEGNGTVMGAELRIVLSTLGEKMTEP E IDS LMOGQEDENGSVHYEDFVKH IMSV VGFDAF LP LLEQQ-DKVQKGTYDDYVEGLRVFDKEGNGTVLGAELRIVLGTMGEKMKEDE IDALMTGQEDDNGCINYEAFVKHVMSV ITFEEF LPMLQAAANNKDQGTFEDFVEGLRVFDKEGNGTVMGAELRHVLATLGEKMTEEEVEELMKGQEDSNGC INYEAFVKH IMSV IEFEQF LPMLQA I SNNKDQGTYEDFVEGLRVFDKEGNGTVMGAELRHVLATLGEKMKEEEVEALMAGQEDSNGCINYEAFVKH IMS I IEFEQF LPMMQA I SNNDQATYEDFVEGLRVFDKEGNGTVMGAELRHVLATLGEKMKEEEVEALMAGQED SNGCINYEAFVKH IMS I IEFEQF LPMMQA I SNNKQGGYEDFVEGLRVFDKEGNGTVMGAELRHVLATLGEKMKEEEVEALLAGQEDSNGCINYEAFVKH IMSV IEFEOF LPMMOA I SNNKDOGGYEDFVEGLRVFDKEGNGTVMGAELRHVLATLGEKMKEEEVEALLAGOEDSNGC INYEAFVKH IMSV IEFEQF LPMLQA I SNNKDQGSYEDFVEGLRVFDKEGNGTVMVTELRHVLATLGEKMKEEEVEALMAGQED SNGCINYEAFVKH IMS I

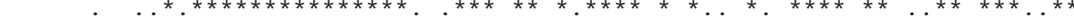

Ancestral $\mathrm{Ca}^{2+}$-binding domain

Fig. 4. Alignment of the deduced amino acid sequences of the myosin light chain 3 (MLC3) proteins. The MLC3-specific domain of avian and mammalian sequences and the ancestral $\mathrm{Ca}^{2+}$-binding domain are indicated in bold type. Conserved residues are marked by an asterisk; conservative differences are marked by a full point. Sources, references and accession numbers are described in Materials and methods.

A

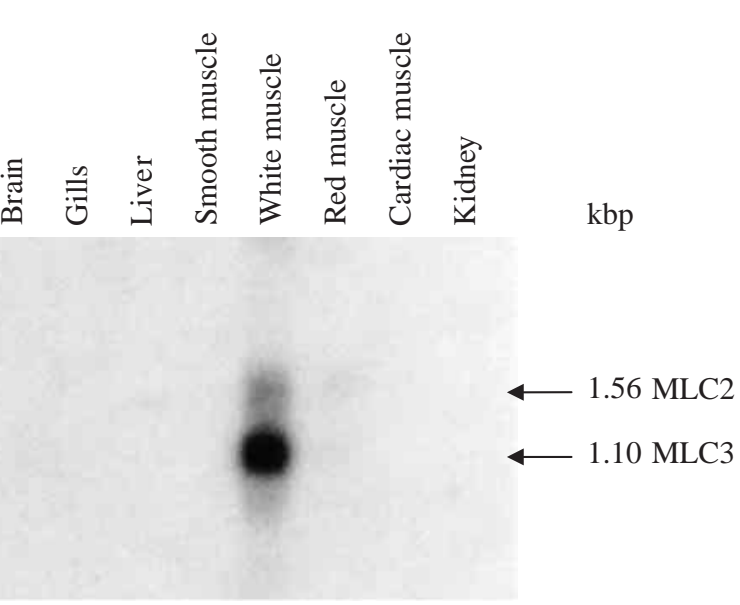

B

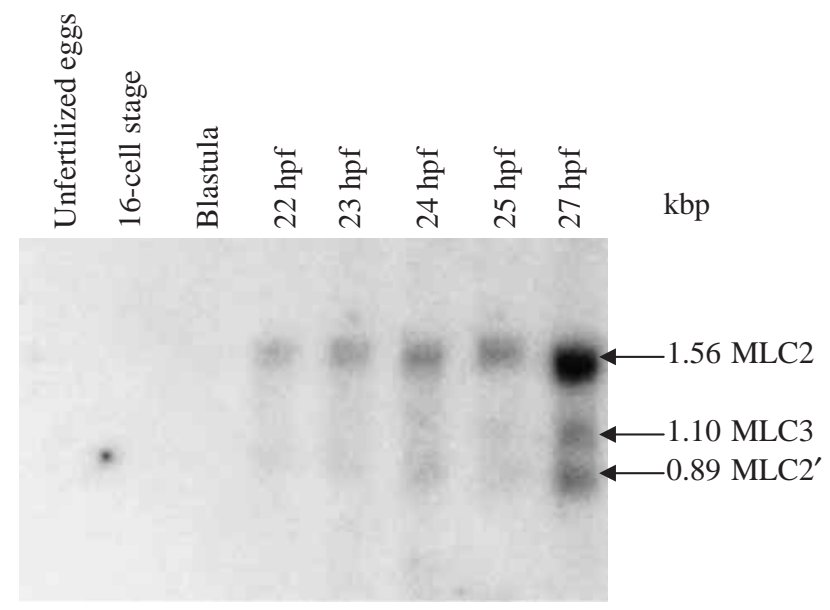

Fig. 5. (A) Tissue-specific transcription of MLC2 and MLC3 genes. Northern blot analysis of total RNA (5 $\mu \mathrm{g})$ from the brain, gills, liver, intestine (smooth muscle), white muscle, red muscle, heart (cardiac muscle) and kidney. (B) RNA expression analysis of MLC2 and MLC3 genes during the development of Sparus aurata; northern blot analysis of total RNA $(5 \mu \mathrm{g})$ from larvae at different stage of development. kbp, kilobase-pairs; hpf, hours post-fertilization. 

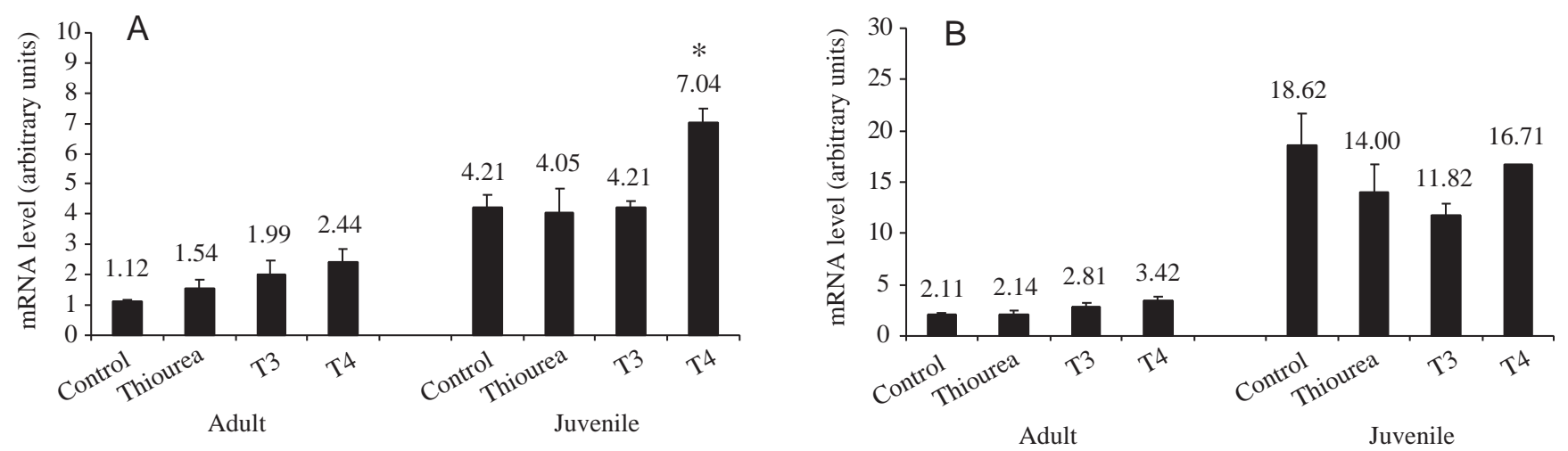

Fig. 6. Effects of experimental hypothyroidism (thiourea treatment) or hyperthyroidism (T3 and T4 treatment) on MLC2 (A) and MLC3 (B) RNA expression of Sparus aurata juvenile or adult individuals. The MLC transcript levels were determined by northern blot analysis, and densitometry was carried out with the resulting autoradiograph for each probe and normalised against the expression of cytoplasmic $\beta$-actin. Values are means + S.E.M. $(N=4)$.

amino acid sequences of MLC2 and MLC3, respectively, constructed by the neighbour-joining method.

For MLC2, D. rerio cardiac MLC2 was used as an outgroup (Fig. 7). The node closest to outgroup tied two large clusters, one formed exclusively by superfast MLC2 and the other containing all the skeletal MLC2 isoforms. Within the latter cluster, mammalian MLC2 formed one group and piscine isoforms formed another (Fig. 7). The piscine clade was supported in $98 \%$ of bootstrap replicates.

For MLC3, M. musculus nonmuscle MLC3 was used as an outgroup (Fig. 8). The phylogenetic analysis revealed two major clusters, one formed from the piscine forms and the other consisting of the mammalian forms. Chicken skeletal MLC3 was clustered together with the mammalian forms. The piscine clade was supported in 100\% of bootstrap replicates.

Phylogenetic analysis and alignment comparisons revealed a high degree of conservation of MLC2 and MLC3 within vertebrates, with $S$. aurata sequences presenting $79 \%$ and $67 \%$ identity respectively to $O$. cuniculus. Moreover, in MLC2, the $\mathrm{Ca}^{2+}$ binding motif appeared to be the region of the protein best conserved.

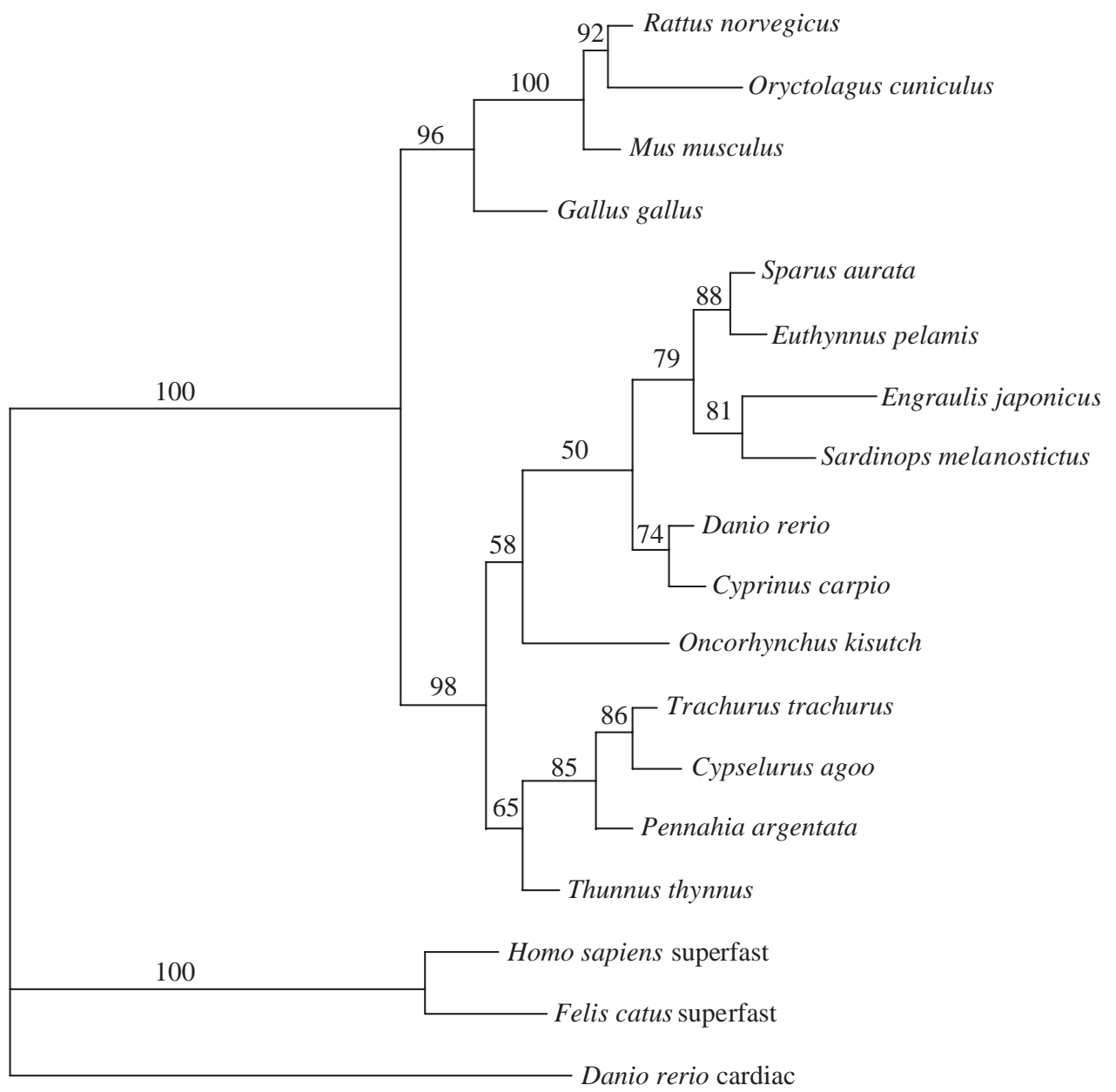

Fig. 7. A phylogenetic tree of myosin light chain 2 (MLC2) sequences constructed using the neighbour-joining method. The lengths of branches are proportional to the phylogenetic distances estimated using Kimura's empirical method for protein distances (Kimura, 1983). Danio rerio cardiac MLC2 is included as an outgroup. Numbers indicate percentages of 100 bootstrap replicates in which the same internal branch was recovered. 


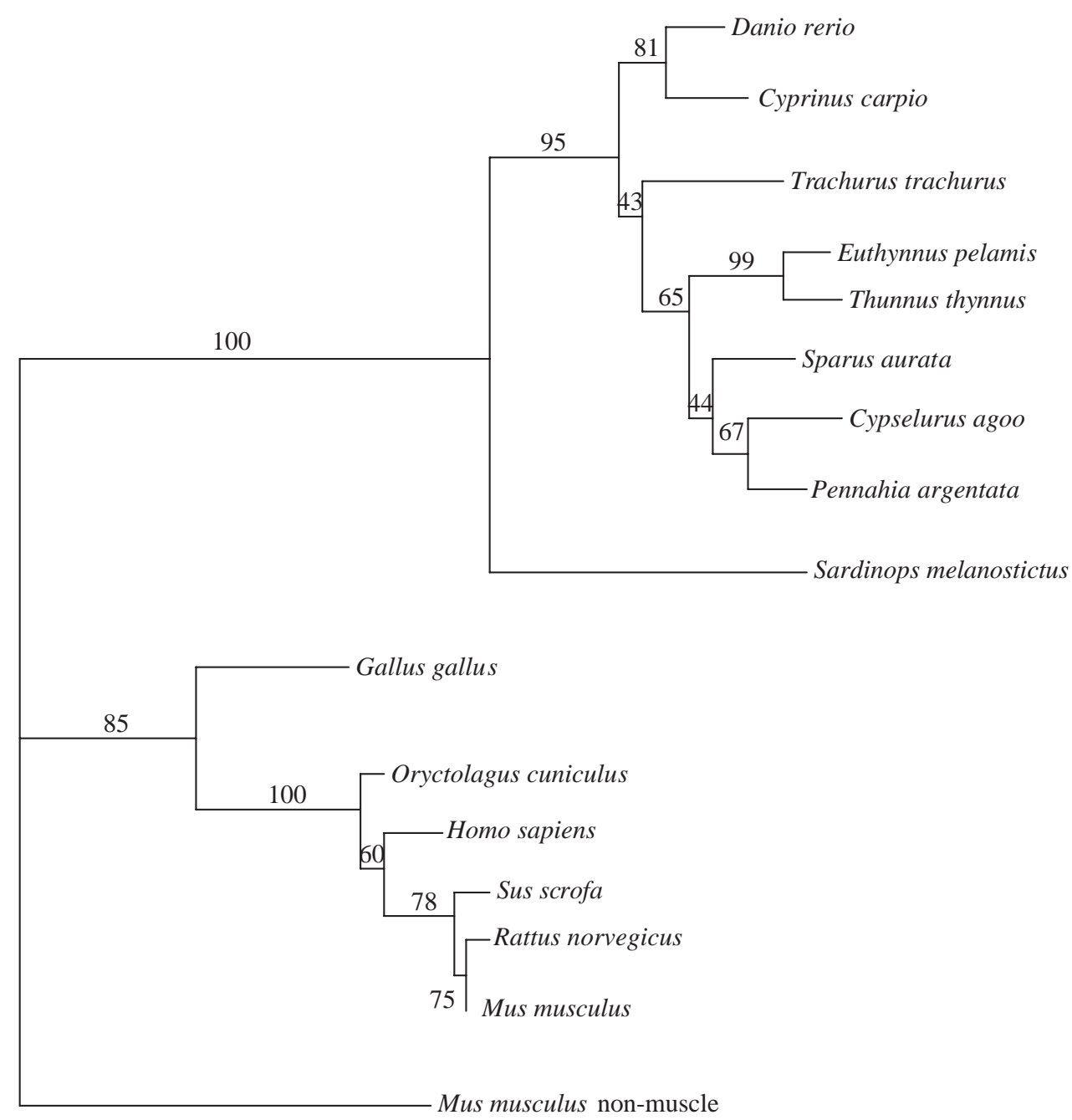

Fig. 8. A phylogenetic tree of myosin light chain 3 (MLC3) sequences constructed using the neighbour-joining method. The lengths of branches are proportional to the phylogenetic distances estimated using Kimura's empirical method for protein distances (Kimura, 1983). Mus musculus non-muscle MLC3 is included as an outgroup. Numbers indicate percentages of 100 bootstrap replicates in which the same internal branch was recovered.

It has been suggested that MLC1, MLC2, MLC3 and troponin $\mathrm{C}$ evolved from a common ancestor and contained four similar $\mathrm{Ca}^{2+}$-binding domains (Qin et al., 1994; Holland et al., 1995), and that an original single $\mathrm{Ca}^{2+}$-binding domain underwent tandem duplications to give a protein with four such domains (Holland et al., 1995). Each of these domains, designated I-IV from the $\mathrm{N}$ terminus, consists of a pair of helices and a central 12-residue $\mathrm{Ca}^{2+}$-binding site. Evolutionary substitutions in amino acid sequences have resulted in the loss of $\mathrm{Ca}^{2+}$-binding ability in some domains. As a result, troponin $\mathrm{C}$ and parvalbumin each have two functional domains, while MLC2 has only domain I (Fig. 2). In MLC3, ancestral domain III appears to be evolutionarily the most conserved (Fig. 4), with a degree of identity within the domain ranging between $82 \%$ and $100 \%$. However, it is controversial whether any MLC3 (alkali) binds $\mathrm{Ca}^{2+}$ (Collins, 1991).
The high degree of conservation between the previously identified MLCs, which is also evident from the newly isolated MLC2 and MLC3, has led to considerable speculation about the evolution of MLC genes in animals (Barton and Buckingham, 1985; Barton et al., 1988; Hailstones and Gunning, 1990; Holland et al., 1995). Although it is generally agreed that MLC genes in vertebrates are derived from the duplication of an ancestral gene, divergent opinions exist about the nature of this ancestral gene. The observation that amphioxus has only one alkali MLC gene has been taken as evidence that duplications occurred after the amphioxus and vertebrate lineages diverged. Since the amino acid sequence of amphioxus alkali MLC is most like the vertebrate embryonic alkali MLC, it is proposed that the ancestral MLC1/3 was probably more like an embryonic form (Holland et al., 1995).

In gilthead sea bream, transcripts of the MLCs isolated could be detected only in white muscle. No other type of muscle expressed either of the MLCs. Individual fish muscle fibres can be categorised as fast or slow on the basis of physiological and molecular criteria that include the expression of different myosin isoforms. The slow and the fast muscle fibres of fishes occupy distinct regions of the body muscle and are involved in different physiological functions. The white, fast glycolytic muscle constitutes the trunk musculature and is specialised for short forceful bursts of activity. Since, in striated muscle, MLC3 content has been positively correlated with the rate of actin filament movement (Lowey and Trybus, 1995), the exclusive expression of MLCs in the white muscle is probably in the context of differential expression profiles of myosin isoforms, which contributes to the functional specialisation of fast muscle with their mechanical and moving properties, implying the existence of a fibre-specific regulatory mechanism of their gene expression.

During development in sea bream, the onset of MLC2 expression was coincident with the start of somitogenesis. MLC3 expression occurred later, when somitogenesis was well advanced. The early appearance of MLC2 transcripts during sea bream development may indicate the absence of embryonic 
forms of this mRNA. However, another MLC2 transcript of smaller size was detectable later in development, and this form may represent either a splicing variant or another MLC2 isoform, which might contribute to the formation of myosin molecules with different contractile properties. In contrast, MLC3 transcripts were detected at the later stages of segmentation, and further work is required to determine whether MLC3 replaces an earlier embryonic form.

The different experimental thyroidal states induced in the present study affected the expression levels of MLC2 only, which is in agreement with the myosin light chain transition pattern observed in metamorphosing flounder (Paralichthys olivaceus) after administration of thyroid hormone (Yamano et al., 1994). Moreover, the results for the expression of MLC2 in juvenile and adult sea bream suggest that the effects of altered thyroidal status were age-related. Thyroid hormone is known to reverse substantially at least some of the changes that occur in ageing muscle ( $\mathrm{Li}$ et al., 1996), while the capacity for myosin heavy chain (MHC type IIA) isoform switching in response to $\mathrm{T} 3$ treatment has been reported to be age-related in rats (Larsson et al., 1995). However, the differential response or lack of response of the two MLCs to varied thyroidal states indicates the existence of different regulatory mechanisms of gene expression in response to thyroid hormones.

In higher vertebrates, it is well established that thyroid hormone induces the foetal-to-adult transition of skeletal muscle MHCs (Gambke et al., 1983; Adams et al., 1999). Thyroid hormones exert their major effects by binding to nuclear receptors (TRs) that act as DNA-binding transcription factors. TRs bind to DNA sequences known as thyroidhormone-responsive elements (TREs) and found in the regulatory regions of target genes and, according to the nature of the TRE, gene expression may be enhanced or inhibited (Wu and Koenig, 2000). In the case of sea bream MLC2, one possibility is that thyroid hormone turns on the first step of a cascade process involving other critical developmental and myogenic factors (e.g. IGF-I, myogenin), which finally activate or inactivate the MLC2 gene, indicating that the MLC2 gene lacks a TRE (Muscat et al., 1995).

Another possibility is that thyroid hormone and its receptor act directly on a TRE present on the MLC2 gene. The latter explanation, however, is not sufficient to support the agerelated pattern of response observed in the present study. During amphibian metamorphosis, mRNAs for thyroid receptors are expressed at high levels in the nervous system but at low levels in muscle (Kawahara et al., 1991). Thus, the thyroidal control of MLC2 via nervous stimulation may be a possible cascade regulatory process. Furthermore, the recent evidence that the regulatory action of thyroid hormone on myosin gene expression is exerted via different type of TR indicates that, in addition to the presence of a TRE on the myosin gene, the expression of the appropriate TR might be a prerequisite for regulation of the gene transcription ( $\mathrm{Yu}$ et al., 2000). TRs have been found to be differentially expressed in different tissues during fish development (Yamano and Miwa,
1998). Thus, myosin gene responsiveness to thyroid hormone might even be regulated at the receptor level.

In summary, two skeletal myosin light chains, MLC2 and MLC3, expressed in the white muscle only of gilthead sea bream, were isolated. Both forms were expressed in sea bream embryos, MLC2 at the start of segmentation and MLC3 in the latter stages of this process. The expression of the isolated MLCs was affected by thyroid hormone status. However, the two MLCs had different expression profiles as well as agerelated responsiveness to experimentally induced thyroidal states, suggesting that their mechanisms of regulation by thyroid hormones are different.

The sequence data reported in this paper have been submitted to EMBL/GenBank data libraries under accession numbers AF150904 (MLC2) and AF149756 (MLC3).

The authors thank C. A. Castanheira do Vale for carrying out the northern blots. The Commission of the European Union, Agriculture and Fisheries specific RTD program, CT96-1742, supported this research.

\section{References}

Adams, G. R., McCue, S. A., Zeng, M. and Baldwin, K. M. (1999). Time course of myosin heavy chain transitions in neonatal rats: importance of innervation and thyroid state. Am. J. Physiol. 276, R954-R961.

Ayson, F. D. and Lam, T. J. (1983). Thyroxine injection of female rabbitfish (Siganus guttatus) broodstock: changes in thyroid hormone levels in plasma, eggs, and yolk-sac larvae, and its effect on larval growth and survival. Aquaculture 109, 83-93.

Barton, P. J. R. and Buckingham, M. E. (1985). The myosin alkali light chain proteins and their genes. Biochem. J. 231, 249-261.

Barton, P. J. R., Cohen, I., Sasson, D., Weydert, A. and Buckingham, M. E. (1988). Structure and sequences of the myosin alkali light chain gene expressed in adult cardiac atria and fetal striated muscle. J. Biol. Chem. 263, 12669-12676.

Brown, C. L., Doroshov, S. I., Nunez, J. M., Hadley, C., Vaneenennaam, J., Nishioka, R. S. and Bern, H. A. (1988). Maternal triiodothyronine injections cause increases in swimbladder inflation and survival rates in larval striped bass, Morone saxatilis. J. Exp. Zool. 248, 168-176.

Brown, C. L., Doroshov, S. I., Cochran, M. D. and Bern, H. A. (1989). Enhanced survival in striped bass fingerlings after maternal triiodothyronine treatment. Fish Physiol. Biochem. 7, 295-299.

Butler-Browne, G. S., Herlicoviez, D. and Whalen, R. G. (1984). Effects of hypothyroidism on myosin isozyme transitions in developing rat muscle. FEBS Lett. 166, 71-75

Cohen-Haguenauer, O., Barton, P. J., Van Cong, N., Cohen, A., Masset, M., Buchingham, M. and Frezal, J. (1989). Chromosomal assignment of two myosin alkali light-chain genes encoding the ventricular/slow skeletal muscle isoform and the atrial/fetal muscle isoform (MYL3, MYL4). Human Genet. 81, 278-282.

Collins, J. H. (1991). Myosin light chains and troponin C: Structural and evolutionary relationships revealed by amino acid sequence comparisons. $J$. Muscle Res. Cell Motil. 12, 3-25.

Collins, C., Schappert, K. and Hayden, M. R. (1992). The genomic organization of a novel regulatory myosin light chain gene (MYL5) that maps to chromosome 4p16.3 and shows different patterns of expression between primates. Human Mol. Genet. 1, 727-733.

Davoli, R., Fontanesi, L., Costosi, E., Zambonelli, P. and Russo, V. (1997). Isolation and sequencing of porcine fast skeletal muscle alkali myosin light chain 3 cDNA. Anim. Biotechnol. 8, 179-185.

Felsenstein, J. (1993). PHYLIP (Phylogeny inference package), Version 3.5c. Department of Genetics, SK-50, University of Washington, Seattle, WA, USA.

Gambke, B., Lyons G. E., Haselgrove, J., Kelly, A. M. and Rubinstein, N. A. (1983). Thyroidal and neural control of myosin transitions during development of rat fast and slow muscles. FEBS Lett. 156, 335-339. 
Gardahaut, M. F., Fontaine-Perus, J., Rouaud, T., Bandman, E. and Ferrand, R. (1992). Developmental modulation of myosin expression by thyroid hormone in avian skeletal muscle. Development 115, 1121-1131.

Gauthier, G. F., Lowey, S., Benfield, P. A. and Hobbs, A. W. (1982). Distribution and properties of myosin isozymes in developing avian and mammalian skeletal muscle fibres. J. Cell Biol. 92, 472-484.

Hailstones, D. L. and Gunning, P. W. (1990). Characterization of human myosin light chains $1 \mathrm{sa}$ and $3 \mathrm{~nm}$ : implications for isoform evolution and function. Mol. Cell. Biol. 10, 1095-1104.

Hailstones, D. L. and Gunning, P. W. (1994). Regulation of nonmuscle myosin light chain 3 gene expression in response to exogenous MLC3nm mRNA. Cell. Mol. Biol. Res. 40, 53-62.

Hill, J. A., Kiessling, A. and Devlin, R. H. (2000). Coho salmon (Oncorhynchus kisutch) transgenic for a growth hormone gene construct exhibit increased rates of muscle hyperplasia and detectable levels of differential gene expression. Can. J. Fish. Aquat. Sci. 57, 939-950.

Hirayama, Y., Kanoh, S., Nakaya, M. and Watabe, S. (1997). The two essential light chains of carp fast skeletal myosin, LC1 and LC3, are encoded by distinct genes and change their molar ratio following temperature acclimation. J. Exp. Biol. 200, 693-701.

Hirayama, Y., Kobiyama, A., Ochiai, Y. and Watabe, S. (1998). Two types of mRNA encoding regulatory light chain in carp fast skeletal muscle differ in their 3' non-coding regions and expression patterns following temperature acclimation. J. Exp. Biol. 201, 2815-2820.

Holland, L. Z., Pace, D. A., Blink, M. L., Kene, M. and Holland, N. D. (1995). Sequence and expression of amphioxus alkali myosin light chain (amphiMLC-alk) throughout development: implications for vertebrate myogenesis. Dev. Biol. 171, 665-676.

Izumo, S., Nadal-Ginard, B. and Mahdavi, V. (1986). All members of MHC multigene family respond to thyroid hormone in a highly tissue-specific manner. Science 231, 597-600.

Johnston, I. A. (1994). Development and plasticity in fish muscle with growth. Basic Appl. Myol. 4, 353-364,

Johnston, I. A, Cole, N. J., Abercromby, M. and Vieira, V. L. A. (1998). Embryonic temperature modulates muscle growth characteristics in larval and juvenile herring. J. Exp. Biol. 201, 623-646.

Kawahara, A., Baker, B. S. and Tata, J. R. (1991). Developmental and regional expression of thyroid hormone receptor genes during Xenopus metamorphosis. Development 112, 933-943.

Kimura, M. (1983). The Neutral Theory of Molecular Evolution. Cambridge: Cambridge University Press.

Larsson, L., Muller, U., Li, X. and Sciaffino, S. (1995). Thyroid hormone regulation of myosin heavy chain isoform composition in young and old rats, with special reference to IIX myosin. Acta Physiol. Scand. 153, 109-116.

Li, X., Hughes, S. M., Salviati, G., Teresi, A. and Larsson, L. (1996). Thyroid hormone effects on contractility and myosin composition of soleus muscle and single fibres from young and old rats. J. Physiol., Lond. 494, 555-567.

Lowey, S. (1994). The structure of vertebrate muscle myosin. In Myology (ed. A.G. Engel and C. Franzini-Armstrong), pp. 485-505. New York: McGrawHill Book Co.

Lowey, S. and Trybus, K. M. (1995). Role of skeletal and smooth muscle myosin light chains. Biophys. J. 68, 120s-127s.

Maeda, K., Muller-Gerhardt, E. and Wittinghofer, A. (1990). Sequence of two isoforms of myosin light chain 2 isolated from a rabbit fast skeletal muscle lambda library. Nucleic Acids Res. 18, 6687.

Muller, B., Maeda, K. and Wittinghofer, A. (1990). Sequence of the myosin light chain $1 / 3$ isolated from a rabbit fast skeletal muscle lambda library. Nucleic Acids Res. 18, 6688.

Muscat, G. E. O., Downew, M. and Dowhan, D. H. (1995). Regulation of vertebrate muscle differentiation by thyroid hormone: the role of the myoD gene family. BioEssays 17, 211-218.

Nabeshima, Y., Fujii-Kuriyama, Y., Muramatsu, M. and Ogata, K. (1982). Molecular cloning and nucleotide sequences of the complementary DNAs to chicken skeletal muscle myosin two alkali light chain mRNAs. Nucleic Acids Res. 10, 6099-6110.

Nudel, U., Calvo, J. M., Shani, M. and Levy, Z. (1984). The nucleotide sequence of a rat myosin light chain 2 gene. Nucleic Acids Res. 12, $7175-7186$.
Ochiai, Y., Watabe, S. and Hashimoto, K. (1988). Physicochemical and immunological properties of myosin light chains from the ordinary muscle of marine teleost fishes. Comp. Biochem. Physiol. 90B, 347-353.

Palermo, J., Gulick, J., Ng, W., Grupp, I. L., Grupp, G. and Robbins, J. (1995). Remodelling the mammalian heart using transgenesis. Cell. Mol. Biol. Res. 41, 501-509.

Periasamy, M., Strehler, E., Garfinkel, L., Gubits, R., Ruiz-Opazo, N. and Nadal-Ginard, B. (1984). Fast skeletal muscle myosin light chain 1 and 3 are produced from a single gene by a combined process of differential RNA transcription and splicing. J. Biol. Chem. 259, 13595-13604.

Perzanowska, A., Gerday, Ch. and Focant, B. (1978). Light chains of trout myosin, isolation and characterization. Comp. Biochem. Physiol. 60B, 295-301.

Power, D. M., Melo, J. and Santos, C. R. A. (2000). The effect of food deprivation and refeeding on the liver, thyroid hormones and transthyretin in sea bream. J. Fish Biol. 56, 374-387.

Qin, H., Morris, B. J. and Hoh, J. F. (1994). Isolation and structure of cat myosin light chain 2 cDNA and evidence for the identity of its human homologue. Biochem. Biophys. Res. Commun. 200, 1277-1282.

Robert, B., Daubas, P., Akimenko, M.-A., Cohen, A., Garner, I., Guenet, J.-L. and Buckingham, M. (1984). A single locus in the mouse encodes both myosin light chains 1 and 3, a second locus corresponds to a related pseudogene. Cell 39, 129-140.

Rowlerson, A., Scapolo, P. A., Mascarello, F., Carpene, E. and Veggetti, A. (1985). Comparative study of myosins present in the lateral muscle of some fish: species variations in myosin isoforms and their distribution in red, pink and white muscle. J. Muscle Res. Cell Motil. 6, 601-640.

Saitou, N. and Nei, M. (1987). The neighbor-joining method: a new method for reconstructing phylogenetic trees. Mol. Biol. Evol. 4, 406-425.

Sanger, F., Nicklen, S. and Coulson, A. R. (1977). DNA sequencing with chain terminating inhibitors. Proc. Natl. Acad. Sci. 74, 5463-5467.

Strehler, E. E., Periasamy, M., Strehler-Page, M. A. and Nadal-Ginard, B. (1985). Myosin light chain 1 and 3 gene has two structurally distinct and differentially regulated promoters evolving at different rates. Mol. Cell. Biol. 5, 3168-3182.

Suzuyama, Y., Umegane, T., Maita, T. and Matsuda, G. (1980). The amino acid sequence of the L-2 light chain of chicken skeletal muscle myosin. Hoppe-Seyler's Z. Physiol. Chem. 361, 119-127.

Thompson, J. D., Higgins, D. G. and Gibson, T. J. (1994). CLUSTAL W: improving the sensitivity of progressive multiple sequence alignment through sequence weighting, position specific gap penalties and weight matrix choice. Nucleic Acids Res. 22, 4673-4680.

Weeds, A. G. and Lowey, S. (1971). Substructure of the myosin molecule. II. The light chains of myosin. J. Mol. Biol. 61, 701-725.

Whalen, R. G., Sell, S. M., Butler-Browne, G. S., Schwartz, K., Bouveret, P. and Pinset-Harstrom, I. (1981). Three myosin heavy chain isozymes appear sequentially in rat muscle development. Nature 292, 805-809.

Wu, Y. and Koenig, R. J. (2000). Gene regulation by thyroid hormone. Trends Endocrinol. Metab. 11, 207-211.

Xu, Y., He, J., Tian, H. L., Chan, C. H., Liao, J., Yan, T., Lam, T. J. and Gong, Z. (1999). Fast skeletal muscle-specific expression of a zebrafish myosin light chain 2 gene and characterization of its promoter by direct injection into skeletal muscle. DNA Cell Biol. 18, 85-95.

Yamano, K. and Miwa, S. (1998). Differential gene expression of thyroid hormone receptor a and b in fish development. Gen. Comp. Endocrinol. 109, $75-85$.

Yamano, K., Takano-Ohmuro, H., Obinata, T. and Inui, Y. (1994). Effect of thyroid hormone on developmental transition of myosin light chains during flounder metamorphosis. Gen. Comp. Endocrinol. 93, 321-326.

Yelon, D., Horne, S. A. and Stainier, D. Y. R. (1999). Restricted expression of cardiac myosin genes reveals regulated aspects of heart tube assembly in zebrafish. Dev. Biol. 214, 23-37.

Yu, F., Göthe, S., Wilkström, L., Forrest, D., Vennström, B. and Larsson, L. (2000). Effects of thyroid hormone receptor gene disruption on myosin isoform expression in mouse skeletal muscles. Am. J. Physiol. 278, R1545-R1554.

Zar, J. H. (1996). Biostatistical Analysis, $3^{\text {rd }}$ edition. Upper Saddle River, NJ, USA. Prentice Hall International, Inc. 